\title{
Research on the Reform of Chinese University Teachers' Evaluation System
}

\author{
Yangqing Zhu \\ Electronic and Information Engineering School \\ Foshan University \\ Foshan, China \\ Email: zhuyangqing_830516@163.com
}

\begin{abstract}
This paper analyzed the current system of teacher evaluation in Chinese universities, and pointed out the problems existing in annual assessment, teaching assessment and scientific research assessment. From the angle of promoting the development of teachers and improving the quality of education, put forward the principle of public, fair and impartial, the principle of combining quantitative and qualitative, the principle of classification assessment and the principle of encouragement as the evaluation criteria of the work of the university teachers in our country. In view of the current situation of university teacher evaluation, put forward measures for teacher evaluation reform and a new conception for constructing a new evaluation system for university teachers.
\end{abstract}

Keywords: Teaching Evaluation; Scientific Research Evaluation; Reform; Improving Teaching Quality

\section{INTRODUCTION}

At present, Chinese higher education is in a period of great development and great change. To improve the overall quality of higher education raise the overall level of personnel training, scientific research and social services, the key is to have a high-quality teacher team. And how to ensure teachers perform their duties, actively input and creatively carry out their work, teacher evaluation is a key factor [1]. Therefore, to establish a scientific and reasonable evaluation system for teachers, to evaluate teachers objectively and impartially, to guide teachers to focus on teaching and research work, to give full play to teachers' enthusiasm and creativity, have a great significance to improving the quality of education. The existed problems in the current teacher assessment system, the principles of teacher assessment and the improvement measures were researched in this paper.

\section{The STATUS AND PROBLEMS OF UNIVERSITY TEACHERS' EVALUATION}

The evaluation of university teachers in China mainly included annual evaluation, scientific research evaluation and teaching evaluation.

\section{A. Annual Evaluation}

The annual evaluation of teachers is a comprehensive assessment, which includes morality, ability, diligence, achievement and so on. The methods of evaluation are mainly descriptive and qualitative assessment, which are generally carried out in departments or colleges. The results are divided into excellent, qualified, basic and unqualified, and the number of each assessment grade is allocated according to the proportion of the total number of staff [2].

There were three main problems in the annual evaluation of teachers. First, the assessment of teachers' professional attributes was not strong, and most of the assessment methods were applied to the management cadres. Second, the assessment content was too macroscopic and abstract, lack of clear index system, the teachers often took the annual personal summary as the substitute. Third, there was not the standard assessment procedure, and the assessment generally delimited the excellent proportion according to the total number of people, but the excellent person were elected in turn. Annual evaluation was a mere formality, and it was difficult to get the effects of assessment and affected the enthusiasm and creativity of teachers.

\section{B. Scientific Research Evaluation}

The assessment of scientific research is specially aimed at the assessment of teachers' scientific research work. The assessment content mainly includes the number and level of the teachers' engaged in scientific research projects, the achievements of the award, the published papers, the promotion of service and the amount of funds obtained. This kind of assessment has the characteristics of quantification, pertinence and maneuverability. The effectiveness of scientific research assessment is heavy and widely used, which is closely related to many vital interests of teachers, teachers mostly concerned about it. Although colleges and universities have a long history of teachers' scientific research evaluation, the accumulated experience is more, the positive effect is more prominent, but the problems of their exposure have also attracted more and more attention from the society [3].

The assessment of teachers' scientific research work mainly includes the following three problems. First, the standard of assessment is not very scientific, and the assimilation of colleges and universities leads to a blind comparison of the assessment of teachers' scientific research. It does not take into account the position and characteristics of the university, which leads to the absence of the status of 
the teaching center and the waste of the allocation of university resources. Second, the evaluation orientation is inaccurate and in pursuit of quantity. At present, many universities have clear quantitative indicators for teachers' scientific research assessment. The main basis of quantification is the grade of journals published, the grade of award-winning achievements, funds and quantity of scientific research projects, but the real quality and level of the paper, the actual contribution of research projects, and other factors that reflect the quality, have not been adequately reflected. Third, the assessment method is too rigid, and the administrative leading color is heavier.

\section{Teaching Evaluation}

Teachers' teaching assessment has been gradually established in recent years in order to conform to the central position of teaching work, and was an assessment system for teachers' teaching work [4].

There were three main problems in the teaching assessment of teachers. First, the content of the assessment was not comprehensive. At present, the main indicators of teaching assessment in Colleges and universities are two aspects: teaching workload and classroom teaching effect. The teaching effect was based on students' evaluation for their teachers' teaching. Some unscientific and imperfect students evaluated teachers' results, which affected the enthusiasm of teachers. In the evaluation of professional titles in the most colleges and universities, the evaluation of teachers' teaching work still stayed in the fuzzy expression of full teaching work and good teaching effect. It was too general to convince people in terms of the numerous indexes of scientific research. Second, the evaluation method was too simple, the assessment standard was too extensive, objective scientific measurement was small, randomness was large, and pertinence was not strong. Third, there was a deviation in the assessment orientation, and the phenomenon of heavy quantity and light quality was also beginning to appear. The quality assessment was replaced by the quantity of teaching work and the number of participating courses, professional construction and teaching reform. The evaluation of teachers' long-term influence on the students, such as dedication, work initiative and enthusiasm were ignored [5].

The above annual assessment, scientific research assessment and teaching assessment are mainly based on the work performance of the teachers, and it is a summary and administrative evaluation. The phenomenon of attaching importance to quantity and despising quality, attaching importance to scientific research and despising teaching was more common. The content of the evaluation was mainly based on the external explicit results of the teachers, ignoring more intrinsic and spiritual values. Now, judging from the effectiveness of the assessment, the methods of assessment were not good enough to achieve the goal of promoting teaching.

\section{THE PRINCIPLE OF EVALUATION FOR TEACHERS IN THE UNIVERSITIES}

Teachers' evaluation should take the development of teachers as the starting point, the actual performance as the yardstick and the quality improvement as the purpose. In the actual operation process, should adhere to the following basic principles.

\section{A. The Principle of Openness, Fairness and Impartiality}

Procedure and process justice are the basic conditions to ensure the evaluation results are fair and reasonable. The formulation of assessment standards should be combined from top to bottom to bottom-up, emphasis on democracy and interaction, according to different levels and different types of teachers, classified and designed index system, assessment standards should have wide consensus. The evaluation procedure should be open and transparent, and academic power should be the dominant force, more professional teachers should be involved. The use of evaluation results should be standardized, and the effectiveness of teachers' assessment results should be ensured.

\section{B. The Principle of Combination of Quantitative and Qualitative}

The combination method of quantitative and qualitative is to improve the objectivity and authenticity of assessment from scientific perspective. Quantification is the basis of qualitative analysis, and qualitative is the starting point and result of quantitative analysis. In the design of evaluation content, strive to comprehensively, truly and accurately measure the performance of teachers. The target of the evaluation should not only highlight the requirements of teachers' teaching and scientific research work, but also pay attention to the teaching effect, the development of teaching reform work, the research on scientific research projects and the value of practice popularization, and strive to achieve the unity of quality and quantity, scientifically and reasonably evaluate the work performance of teachers [6].

\section{Principle of Classification Assessment}

Classification is the key to ensure the assessment of science and improve the effectiveness of assessment. In different types, levels, and stages of development of universities should have different assessment criteria for teachers' assessment, reflecting the orientation of operating university and their pursuit of characteristics. Colleges and universities should have different criteria and incentives for different classes of teachers, such as teaching assistants, lecturers, associate professors and professors, and different classes of courses, such as specialized courses, basic courses and bilingual teaching. From the perspective of human development, it should be classified and evaluated, allowing teachers to choose different path of professional development, fully mobilize the enthusiasm and creativity of all teachers, make great efforts to make the people with academic 
research grow up and innovate the practice, let the teachers willing to teach to cultivate the students, and let the teachers dedicate to the scientific research.

\section{Incentive Principle}

Motivation is an indispensable part and activity in the management process. Effective assessment encouragement is the motive force for teachers' work. The professional work of teachers is a special field in social activities. In the use of the means of assessment, motivation should be taken as the core, and the teachers' sense of cause, responsibility and achievement should be strengthened. The assessment subject should respect the teachers' wishes and emotions, based on the teachers' existing foundation, and focus on the teachers' future professional development and their potential, so as to promote the improvement of teaching quality and the sustainable development of the university.

\section{MEASURES FOR THE REFORM OF UNIVERSITY TEACHERS' EVALUATION}

\section{A. Continuous Improvement of College Teachers' Teaching Performance Assessment System}

The thirty-first article in the law of Higher Education in People's Republic of China stipulates that "colleges and universities should take the training of talents as the center to carry out teaching, scientific research and social services, to ensure the quality of education and teaching to meet the national standards". Cultivating students, scientific research and social services is the three major function of universities. Cultivating students is the first duty of colleges and universities. Otherwise, they are scientific research institutes, not university. The main function of every university is to rely on teachers and cultivate students through teaching [7].

The assessment of teachers' performance should focus on three aspects: teaching workload, teaching effect, teaching research and reform.

(1) Teachers should undertake certain teaching tasks. The teaching workload of different professional title teachers should have the lowest and maximum limit. The minimum standard is not reached, and the assessment is unqualified. But the amount is not higher and better, should be reasonably determined according to the actual situation. For young teachers who have not long been on the post of teachers, they should reduce the assessment requirements of the teaching work, let them have more time to go to the society, enter into production line, enrich practical experience, engage in scientific research, and lay a foundation for improving their teaching ability. At present, we should emphasize that professors teach classes for students, so that the majority of students can receive the edification of high-quality educational resources [8].

(2) Should achieve good teaching results. Teaching objects are students, and students are the basic participants in educational activities. Students are the subject to evaluate teachers' teaching effect, and students' evaluation information about teaching process and effect is important and unique. In order to ensure that students evaluating teachers are the scientificity and accuracy, we should improve the system design from the aspects of evaluation contents and evaluation methods. This should learn more about the successful experience of student assessment teaching in advanced countries. American universities have many specific and unique requirements for classroom teaching. The content is vivid and observable, which is enough to attract students to make an objective and accurate evaluation. At the same time, the score of peer evaluation teaching should be improved, because only peers can truly understand the difficulty, degree, progress and effect of the same and similar courses. To enhance the strength of teaching supervision and leadership evaluation, to form a community where teachers, supervisors and leaders improve teaching and learning [9].

(3) Teachers should carry out teaching research. This is the prerequisite and basis for improving the teaching level of teachers, mainly including the teaching research projects undertaken by teachers, the construction of teaching resources and the effect of their application to teaching practice. Teaching research is an important part of scientific research in Colleges and universities, and is also an important responsibility of teachers. Only through teaching research and reform practice, teachers can expand their horizons and improve their own quality, so as to ensure the quality of teaching.

\section{B. The Focus of University Teachers' Scientific Research Assessment should turn to Quality and Innovation}

Compared with teaching assessment, scientific research assessment can be quantified with many indicators, clear guidance, strong operability and smooth implementation. But as time goes on, the assessment of the quality and the actual results of scientific research have been paid more and more attention. On the basis of a comprehensive summary of the important role of the original scientific research assessment, the universities should change the evaluation model based on quantity, formulate science research assessment method of more scientific and clear guidance.

(1) Should improve the assessment of teachers' research projects, papers quality and their impact on production practice and social development. To the assessment of University teachers' scientific research, should strength the assessment of scientific research for teaching of back feeding, in order to reflect the educational function of scientific research activities of university teachers.

(2) Should attach importance to the practical contribution of teachers in technology development, consultation and science technology extension, and emphasize their theoretical and practical values, and lay stress on practicality. The combination of production, teaching and research is an important strategic move for the continuous development and progress of a country and an industry. According to the successful experience of some universities in Europe and the United States, the combination 
of production, teaching and research is the most effective and convenient way. The key point of the research assessment of university teachers is to guide the teachers to go deep into the society and enterprise, to achieve the project from the enterprise, and to serve the industrial transformation and upgrading, the technological innovation and the solution of the problems. Scientific research has vitality and value only if it solves the problems in the actual production and social development.

(3) Flexible arrangement of University Teachers' scientific research evaluation cycle. At present, University teachers' scientific research assessment stipulates that university teachers must complete a certain amount of scientific research output within one year. Scientific research is not something that can be accomplished in a short time. Great achievements in scientific research have a long process of research and practice. Once a year's assessment can only make academic short-term successes and quick profits, it is hard for teachers to really concentrate on scientific research. Every teacher should be able to independently determine the assessment cycle according to his own professional development. Colleges and universities should cancel annual evaluation, carry out assessment according to their employment periods and create a relaxed academic environment for teachers' scientific research [10].

\section{Effective Establishment of the Equivalent Evaluation Mechanism of Teaching and Scientific Research}

The most important activity of colleges and universities is teaching, which is also the main feature different from other higher education institutions and research institutes. It is precisely because of the importance of teaching, that teachers' achievements in teaching should be valued and recognized. At present, under the situation that the emphasis on scientific research is more common, colleges and universities need to establish and improve the effective interaction between teaching and scientific research through the establishment and improvement of the equivalent evaluation mechanism, and further improve the teaching construction and improve the quality of education. In the activities of teacher evaluation, job engagement and professional development, should strengthen the assessment of teachers' teaching performance. Colleges and universities build the equivalent evaluation mechanism of teaching achievements and scientific research achievements, and strongly commend the outstanding teachers who have made outstanding contributions in the teaching line, to stimulate teachers' enthusiasm and improve the quality of teaching.

\section{SUMMARY}

The teaching and scientific research activities involved in the evaluation of college teachers are characterized by creativity, comprehensiveness, long-term and individual differences, and service objects are mainly human, and their work is difficult to quantify. It needs to be perfected and continuously optimized in the process of practice, and it is moving towards the direction of promoting the development of teachers and improving the quality of work.

\section{REFERENCES}

[1] Zhou Yurong, Shen Hong, The Effect of the Current Faculty Evaluation on Faculty Development Based on a Perspective of driving Force, TsingHua Journal of Education, Beijing, vol.37(5), pp.54-61, September 2016.

[2] Li Haoluan, Zheng Yang, Research on Innovation of Post Performance Appraisal System in Universities, Journal of Shenyang Institute of Engineering( Social Sciences), ShenYang, vol.11(1), pp. 105-109, January 2015.

[3] Wu Luhan, Thinking and Practice Exploration on the Reform of Scientific Research Assessment in Colleges and Universities, Science \& Technology Ecnony Market, Nanchang, PP. 111-113, June 2018.

[4] Zhu Fei, China University Teachers' Teaching and Research at Present: Problems and Solutions, Journal of Zhengzhou Normal Education, Zhengzhou, vol.6(4), pp. 13-18, July 2017.

[5] Sun Lizhi, Return of Value Rationality : Inevitable Route of University Teachers' Teaching Development, Heilongjiang Researches on Higher Education, Haerbin, Vol.288, pp. 96-99, April 2018.

[6] Zhang Jiming, zhang Lili, Teacher-oriented University Concept: System Practice and Reform, Review of Higher Eduction, Jinan, vol. 46, pp. 36-41, March 2018.

[7] The law of Higher Education in People's Republic of China, People's daily , Beijing, 016 Edition, March 30, 2016.

[8] Li Jiahui, Ye Xiaojuan, A New Path for University Teachers' Professional Development based on the Academic Dimension of Teaching, Jinan, Contemporary Education Research and Teaching Practice, Shijiazhuang, pp. 90-91, April 2018.

[9] Wang Yan, A Comparative Study of Teacher Evaluation System between China and the USA on the Perspective of Teaching Scholarship, Modern Education Science, Changchun, pp. 68-73, March 2018.

[10] Huang Yongliang, Research on the Construction of University Teachers' Performance Evaluation System based on Teachers' Independent Development, Journal of Socialist Theory Guide, Xian, pp. 104-110, June 2018. 